\title{
Correction to: Long-term outcomes and surveillance timing of patients with large non-pedunculated colorectal polyps with histologically incomplete resection in endoscopic resection
}

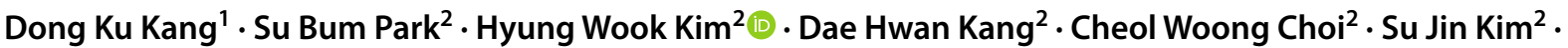 \\ Hyeong Seok $\mathrm{Nam}^{2}$. Dae Gon Ryu ${ }^{2}$. Jeong Seok Lee ${ }^{3}$
}

Published online: 17 March 2021

(c) The Author(s), under exclusive licence to Springer Science+Business Media, LLC, part of Springer Nature 2021

\section{Correction to: Surgical Endoscopy https://doi.org/10.1007/s00464-021-08419-9}

The article was updated to include the Article Note that Dong Ku Kang and Su Bum Park contributed equally to this work and share first authorship.
Publisher's Note Springer Nature remains neutral with regard to jurisdictional claims in published maps and institutional affiliations.

Dong Ku Kang and Su Bum Park contributed equally to this work and share first authorship.

The original article can be found online at https://doi.org/10.1007/ s00464-021-08419-9.

Hyung Wook Kim

mdkhwook@gmail.com

1 Department of Internal Medicine, Gupo Sungshim Hospital, Busan, Korea

2 Department of Internal Medicine, Pusan National University School of Medicine and Research Institute for Convergence of Biomedical Science and Technology, Pusan National University Yangsan Hospital, Beomeo-ri, Mulgeum-eup, Gyeongsangnam-do 626-770, Yangsan, Korea

3 Department of Internal Medicine, Gwanghye General Hospital, Busan, Korea 